\title{
Late Results of Autogenous Vein Bypass Grafts in Femoropopliteal Arterial Occlusion
}

\author{
R. M. BADDELEY, ${ }^{*}$ CH.M., F.R.C.S. ; F. ASHTON, $†$ CH.M., F.R.C.S. \\ G. SLANEY, $\ddagger$ CH.M., F.R.C.S. ; A. D. BARNES, $\$ CH.M., F.R.C.s.
}

\begin{abstract}
Cummary: The outcome of 185 consecutive autogenous vein bypass grafts for femoro-popliteal occlusions carried out between January 1962 and June 1968 has been reviewed. One patient died at operation and 21 late deaths have occurred since. The overall five-year patency was $61.5 \%$, but was much lower when the popliteal-tibial runoff arteries were diseased. Distal anastomosis of the graft to the popliteal artery below the level of the knee joint also impaired the results, and if this was performed with a graft of minimal diameter less than $5 \mathrm{~mm}$. sustained patency was obtained in only a quarter of the limbs. Nevertheless, where major amputation was imminent owing to advanced ischaemia three out of four limbs were salvaged.
\end{abstract}

\section{Introduction}

In 1967 we reported moderately satisfactory results with autogenous long saphenous vein bypass grafts in the treatment of femoro-popliteal occlusive disease, which, though accepted as the best available reconstructive procedure in the palliation of a difficult vascular problem, still remains to be justified by long-term results. Late patency in over $85 \%$ of cases in some large series (Linton and Darling, 1962; Szilagyi et al., 1964; Gutelius et al., 1965; DeWeese et al., 1966) was not emulated by the two-year patency rate in our series, which was $67 \%$. More recently, Darling et al. (1967) reported a five-year patency of $73 \%$, but others have expressed doubt regarding the long-term efficacy of venous bypass grafts in the thigh. For this reason we have reviewed the results in our patients again, now that a substantial number have reached the five-year follow-up stage.

\section{Patients Studied}

From January 1962 to June 1968185 autogenous vein bypass grafts were implanted in 164 patients (17 of whom were women) and their outcome was followed to January 1969. Symptoms were bilateral in 83 patients, and 21 of these had reconstructive surgery in both limbs. The ages of the limbs at the time of operation are summarized in Table I. Presenting symptoms

*Consultant Surgeon, the General Hospital, Birmingham 4.

†Senior Lecturer, Department of Surgery, University of Birmingham Medical School, Queen Elizabeth Hospital, Birmingham 15.

‡Professor of Surgery, University of Birmingham Medical School, Queen Elizabeth Hospital, Birmingham 15 .

SConsultant Surgeon, Queen Elizabeth Hospital, Birmingham 15.
TABLE I.-Age Distribution

\begin{tabular}{|c|c|c|c|c|c|c|c|}
\hline \multirow{2}{*}{\multicolumn{5}{|c|}{ Age }} & \multirow{2}{*}{ No. of Limbs } & \multicolumn{2}{|c|}{ Graft Failures } \\
\hline & & & & & & No. & $\%$ \\
\hline $\begin{array}{l}<40 \text { years } \\
40-49 " \\
50-59 " \\
60-69 " \\
70-79 "\end{array}$ & $\begin{array}{l}\cdots \\
\cdots \\
\cdots\end{array}$ & $\begin{array}{l}\cdots \\
\cdots \\
\cdots\end{array}$ & $\begin{array}{l}\cdots \\
\cdots \\
\cdots\end{array}$ & $\begin{array}{l}\cdots \\
\cdots \\
\cdots\end{array}$ & $\begin{array}{r}9 \\
28 \\
67 \\
72 \\
9\end{array}$ & $\begin{array}{r}4 \\
10 \\
17 \\
26 \\
1\end{array}$ & $\begin{array}{l}44 \cdot 4 \\
35 \cdot 7 \\
25 \cdot 4 \\
36 \cdot 1 \\
11 \cdot 1\end{array}$ \\
\hline & & & & & 185 & 58 & $31 \cdot 4$ \\
\hline
\end{tabular}

were intermittent claudication in 165 legs, but rest pain and trophic changes were present in 71 , and 49 had ulceration or gangrene. Four patients suffering from acute superficial femoral artery trauma due to gunshot or road traffic accidents, six cases of femoral aneurysm (four of which presented with intermittent claudication), and three popliteal aneurysms (each showing distal ischaemia) have also been included. In 150 limbs symptoms had been present for more than six months; the remaining 35 with shorter histories underwent early operation for advanced ischaemia jeopardizing limb survival. Claudicants had impaired exercise tolerance which, in most cases, limited their walking distance to 150 yards (140 metres) or less, along a flat hospital corridor at "normal" pace.

Arteriography by the Seldinger or translumbar technique was carried out in all patients, and occasionally on-table femoral arteriography was employed to visualize the state of the runoff vessels.

Other routine investigations performed included electrocardiogram, serum biochemical profile, blood sugar, cholesterol and urea, a full blood examination, and creatinine clearance. Dyspepsia was investigated because of the dangers associated with anticoagulant therapy in peptic ulceration and because of the age of the patients concerned; evidence of malignancy was also routinely sought. The surgical technique for reversed autogenous vein bypass graft remains as we previously reported (Baddeley et al., 1967).

At the follow-up examination grafts were designated successful if the graft itself or pedal pulses were palpable. This was usually accompanied by relief of intermittent claudication and lack of other evidence of ischaemia, though in four patients with functioning grafts recurrence of rest pain or ulceration, due to progress of distal occlusive disease, developed before ultimate occlusion occurred and major amputation became necessary. All surviving patients were examined at routine clinic attendances except in 12 instances where the help of each patient's general practitioner was enlisted. 


\section{Results}

Of the total of 185 grafts 58 have occluded in a follow-up period of six months to nine years. Of the 164 patients $22(13 \%)$ subsequently died from the following causes: myocardial infarction (9), congestive cardiac failure (2), cerebrovascular accident (8), malignancy (2), and one where the cause was unknown. Only one death occurred within 28 days of operation -an operative mortality rate of $0.6 \%$. In 12 patients the graft was patent and in 10 occluded at the time of death, so that of all patients who died $55 \%$ had functioning grafts at the time of their death.

\section{Graft Patency}

In calculating patency rate the number of deceased patients has been deducted from the total number of graft operations annually, the percentage patency being calculated from the survivors alone. Thus 32 grafts were performed five years or more ago, and of the 26 survivors 16 still have patent grafts; a five-year patency rate of $61.5 \%$.

Table II shows that five grafts occluded either at operation

TABLE II.-Duration of Follow-up and Late Patency

\begin{tabular}{|c|c|c|c|c|c|}
\hline \multirow{2}{*}{$\begin{array}{l}\text { Duration of } \\
\text { Follow Up }\end{array}$} & \multirow{2}{*}{$\begin{array}{l}\text { Total No. } \\
\text { of Grafts }\end{array}$} & \multirow{2}{*}{ Deaths } & \multirow{2}{*}{$\begin{array}{l}\text { No. of Grafts } \\
\text { Followed Up }\end{array}$} & \multicolumn{2}{|c|}{ Patent Grafts } \\
\hline & & & & No. & $\%$ \\
\hline 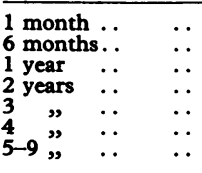 & $\begin{array}{r}185 \\
185 \\
182 \\
141 \\
109 \\
77 \\
32\end{array}$ & $\begin{array}{r}1 \\
2 \\
3 \\
5 \\
9 \\
10 \\
6\end{array}$ & $\begin{array}{r}184 \\
183 \\
179 \\
136 \\
100 \\
67 \\
26\end{array}$ & $\begin{array}{l}179 \\
162 \\
142 \\
102 \\
68 \\
43 \\
16\end{array}$ & $\begin{array}{l}97 \cdot 3 \\
88.5 \\
79.3 \\
75.0 \\
68.0 \\
64.2 \\
61.5\end{array}$ \\
\hline
\end{tabular}

or during the subsequent 28 days, giving an initial patency rate at discharge from hospital of $97.3 \%$, falling to $88.5 \%$ at six months; $79.3 \%$ at one year, and $75 \%$ at two years; these figures are better than those at comparable stages in our previous report. At the three-, four-, and five-year follow-up stages the patency rates were $68 \%, 64.2 \%$ and $61.5 \%$ respectively.

\section{Age, Length of Block, Graft Occlusion}

Most patients were between 50 and 69 years of age. The failure rate of grafts was lowest when performed in the 50-59 decade and, surprisingly, there was little difference between patients undergoing operation in the fifth and seventh decades of life (Table I). The mean failure rate for patients under the age of 50 years was slightly higher $(37.8 \%)$ than that of patients over that age (30.0\%).

Of the 167 atherosclerotic occlusion cases with arteriograms available for study 67 had short segmental occlusions $(15 \mathrm{~cm}$. or less as measured on the arteriogram) and 100 had long occlusions (usually the whole length of the superficial femoral artery). Patency was maintained in $67.2 \%$ and $66 \%$ respectively.

Progression of femoro-popliteal occlusive disease was shown by Tillgren et al. (1963) to vary inversely with age. They also found that short occlusions had a much greater tendency to progression than longer ones. In the present series the similar results in the various age groups and in lengths of arterial occlusion indicate that the bypass graft overcame these detrimental factors by shunting blood around the part of the femoro-popliteal segment most often diseased. The alternative surgical technique, thromboendarterectomy, is inadequate in this respect, as we have already emphasized (Baddeley et al., 1968).

\section{Patency Rate Related to Popliteal Tibial Run-off}

As in our previous report, the status of the popliteal and tibial outflow arteries, generally referred to as "run-off," was graded as follows: "excellent" (popliteal and tibial vessels of normal calibre), "good" (minimal disease of the popliteal and tibial arteries), "moderate" scalloping of the popliteal artery and occlusion of one of the three main calf arteries and narrowing of the others), or "poor" (as for moderate except for occlusion of two or all three calf arteries). The patency rate for good, moderate, and poor run-offs (Tables III-V) show good values at one month in each group. It is notable that patency declined to $14 \%$ at three years when the run-off was poor but remained satisfactorily high at $77 \%$ at the same stage with good run-off. Surprisingly, the moderate run-off limbs were equally as good as the latter for two years but declined more rapidly thereafter.

TABLe III.-Survival and Graft Patency in Patients with Good PoplitealTibial Run-off

\begin{tabular}{|c|c|c|c|c|c|c|c|}
\hline \multirow{2}{*}{\multicolumn{2}{|c|}{ Duration }} & \multirow{2}{*}{$\begin{array}{c}\text { No. of } \\
\text { Patients }\end{array}$} & \multirow[t]{2}{*}{ Deaths } & \multirow[t]{2}{*}{ Survivors } & \multicolumn{2}{|c|}{ Patent Grafts } & \multirow[b]{2}{*}{ No. Failed } \\
\hline & & & & & No. & $\%$ & \\
\hline 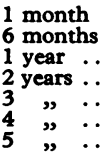 & $\begin{array}{l}\ldots \\
\because \\
\cdots \\
\cdots \\
\therefore\end{array}$ & $\begin{array}{l}85 \\
85 \\
85 \\
67 \\
53 \\
38 \\
20\end{array}$ & $\begin{array}{l}\bar{Z} \\
\overline{2} \\
1 \\
1 \\
-\end{array}$ & $\begin{array}{l}85 \\
85 \\
85 \\
65 \\
52 \\
37 \\
20\end{array}$ & $\begin{array}{l}83 \\
76 \\
71 \\
50 \\
40 \\
27 \\
13\end{array}$ & $\begin{array}{l}97 \cdot 6 \\
89 \cdot 4 \\
83 \cdot 5 \\
76 \cdot 9 \\
76 \cdot 9 \\
73 \cdot 0 \\
65 \cdot 0\end{array}$ & $\begin{array}{r}2 \\
9 \\
14 \\
15 \\
12 \\
10 \\
7\end{array}$ \\
\hline
\end{tabular}

TABLE IV.-Survival and Graft Patency in Patients with Moderate PoplitealTibial Run-off

\begin{tabular}{|c|c|c|c|c|c|c|c|}
\hline \multirow{2}{*}{\multicolumn{2}{|c|}{ Duration }} & \multirow{2}{*}{$\begin{array}{l}\text { No. of } \\
\text { Patients }\end{array}$} & \multirow[t]{2}{*}{ Deaths } & \multirow[t]{2}{*}{ Survivors } & \multicolumn{2}{|c|}{ Patent Grafts } & \multirow[t]{2}{*}{ No. Failed } \\
\hline & & & & & No. & $\%$ & \\
\hline 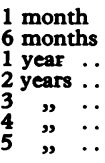 & $\begin{array}{l}\cdots \\
\cdots \\
\cdots \\
\cdots \\
\cdots\end{array}$ & $\begin{array}{r}46 \\
46 \\
45 \\
32 \\
22 \\
11 \\
4\end{array}$ & $\begin{array}{l}\bar{z} \\
\frac{1}{1} \\
\frac{1}{1}\end{array}$ & $\begin{array}{r}46 \\
46 \\
45 \\
31 \\
21 \\
11 \\
3\end{array}$ & $\begin{array}{r}45 \\
43 \\
36 \\
24 \\
13 \\
5 \\
2\end{array}$ & $\begin{array}{l}97 \cdot 8 \\
93.5 \\
80.0 \\
77 \cdot 4 \\
61 \cdot 9 \\
45.5 \\
50.0\end{array}$ & $\begin{array}{l}1 \\
3 \\
9 \\
7 \\
8 \\
6 \\
1\end{array}$ \\
\hline
\end{tabular}

Table V. - Survival and Graft Patency in Patients with Poor PoplitealTibial Run-off

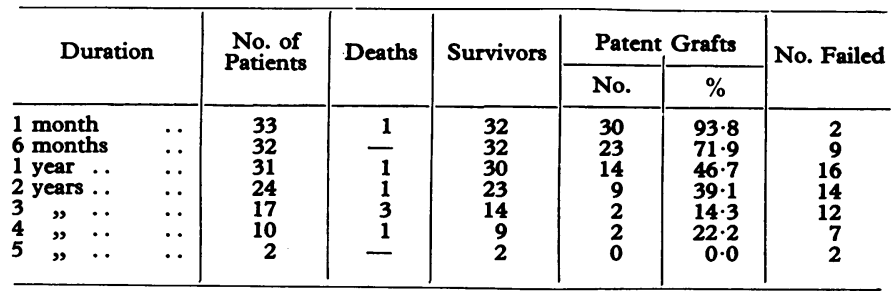

\section{Patency, Graft Diameter, Site of Distal Anastomosis}

The minimal diameter of the implanted vein grafts was noted at 131 operations. In 29 instances this was less than $5 \mathrm{~mm}$.; 16 have since occluded, the patency rate therefore being $44.8 \%$. In 102 limbs the graft was $5 \mathrm{~mm}$. or more in minimal diameter, and here the patency rate was $76.5 \%, 24$ having occluded.

The distal site of graft anastomosis to the popliteal artery was noted at 169 operations to be above the level of the knee joint in 90 instances, below the joint line in 70 , and at joint level in 9. The outcome of these grafts is summanized in Table VI. It can be seen that when the distal insention was below knee-joint level patency was appreciably lower.

TABle VI.-Patency Related to Site of Distal Anastomosis

\begin{tabular}{|c|c|c|c|c|c|}
\hline \multirow{2}{*}{\multicolumn{2}{|c|}{ Level of Anastomosis }} & \multirow{2}{*}{ No. of Grafts } & \multicolumn{2}{|c|}{ Patent Grafts } & \multirow{2}{*}{ No. Occluded } \\
\hline & & & No. & $\%$ & \\
\hline $\begin{array}{l}\text { Above knee joint } \\
\text { Below knee joint } \\
\text { At knee joint }\end{array}$ & $\ddot{*}$ & $\begin{array}{r}90 \\
70 \\
9\end{array}$ & $\begin{array}{r}72 \\
36 \\
6\end{array}$ & $\begin{array}{l}80.0 \\
51.4 \\
66.7\end{array}$ & $\begin{array}{r}18 \\
34 \\
3\end{array}$ \\
\hline
\end{tabular}


To clarify the question of whether the poor results with grafts of less than $5 \mathrm{~mm}$. diameter were due to a high incidence of distal below-knee anastomoses, Table VII compares the

TABLE VII.-Patency, Graft Diameter, and Site of Distal Anastomosis

\begin{tabular}{ll|c|c|c|c|c}
\hline \multicolumn{1}{c|}{$\begin{array}{c}\text { Anastomosis } \\
\text { Level }\end{array}$} & Diameter & \multirow{2}{*}{$\begin{array}{c}\text { No. of } \\
\text { Cases }\end{array}$} & \multicolumn{2}{|c|}{ Patent Grafts } & $\begin{array}{c}\text { No. } \\
\text { Occluded }\end{array}$ \\
\cline { 5 - 6 } & & & No. & $\%$ & \\
\hline Above knee & $\cdots$ & $5 \mathrm{~mm} .(+)$ & 55 & 47 & 85.5 & 8 \\
$\begin{array}{ll}\text { Above knee } \\
\text { Below knee }\end{array}$ & $\cdots$ & $<5 \mathrm{~mm}$. & 13 & 8 & 61.5 & 5 \\
Below knee & $\cdots$ & $<5 \mathrm{~mm} .(+)$ & 35 & 22 & 62.9 & 13 \\
\hline
\end{tabular}

outcome in the combinations of these factors. Though the numbers are small the results indicate that patency rate in grafts of satisfactory calibre is lower when anastomosis is below the knee joint, and that the combination of a narrow graft and a below-knee insention yields very poor results.

A further question arising from observation of the poorer results of below-knee distal anastomoses is whether these were due to more advanced atherosclerotic change in the run-off vessel. The results correlating these two factors (Table VIII)

TABLE VIII.-Patency Related to Run-off Status and Level of Graft Insertion

\begin{tabular}{|c|c|c|c|c|c|}
\hline \multirow{2}{*}{ Run-off } & \multirow{2}{*}{ Anastomosis } & \multirow{2}{*}{ No. of Grafts } & \multicolumn{2}{|c|}{ Patent Grafts } & \multirow{2}{*}{ No. Occluded } \\
\hline & & & No. & $\%$ & \\
\hline $\begin{array}{l}\text { Good } \quad . \\
\text { Moderate } \\
+ \text { Poor } \quad .\end{array}$ & $\begin{array}{l}\text { Above knee } \\
\text { Below knee } \\
\text { Above knee } \\
\text { Below knee }\end{array}$ & $\begin{array}{l}44 \\
31 \\
32 \\
35\end{array}$ & $\begin{array}{l}38 \\
15 \\
20 \\
18\end{array}$ & $\begin{array}{l}86 \cdot 4 \\
46 \cdot 1 \\
62 \cdot 5 \\
51 \cdot 4\end{array}$ & $\begin{array}{r}6 \\
16 \\
17 \\
12\end{array}$ \\
\hline
\end{tabular}

show a pronounced deterioration in patency even with good run-off when the grafts were implanted distal to the knee-joint. In more advanced distal disease as shown by moderate and poor run-offs the difference, though still persisting, is less evident.

\section{Salvage of Limbs}

Advanced ischaemia sufficient to cause rest pain, trophic changes, ulceration, or gangrene usually indicates that a major amputation is imminent. Ninety legs came into this category, and vein grafts still remain patent in 48 of them. Though the remaining 42 grafts have occluded, major amputation was subsequently necessary in only 19, which means that 67 legs were saved from a major amputation, a salvage rate of $74.4 \%$. Even where the limb was in a terminal state as indicated by overt gangrene or ulceration, 33 out of $49(67.4 \%)$ legs were salvaged, half of them retaining functioning bypass grafts. Thus even though subsequent late failure of a graft may occur a good functioning limb may remain, albeit showing some residual evidence of vascular insufficiency. This "tiding over" concept has been emphasized previously by ourselves and others, and merits wider recognition.

\section{Postoperative Anticoagulant Therapy}

Phenidione or warfarin therapy was begun 48 hours postoperatively and continued without interruption in 67 patients. The effect of these drugs on the outcome of grafts, together with the influence of other factors already mentioned, is summarized in Table IX.

Unfortunately, only limited significance can be attributed to these findings as selection for therapy was not properly randomized. They do, however, indicate the need for further properly controlled examination of the efficacy of the drugs as
TABLE IX.-Patency Related to Anticoagulant Therapy, Site of Graft Insertion, Run-off, and Graft Diameter

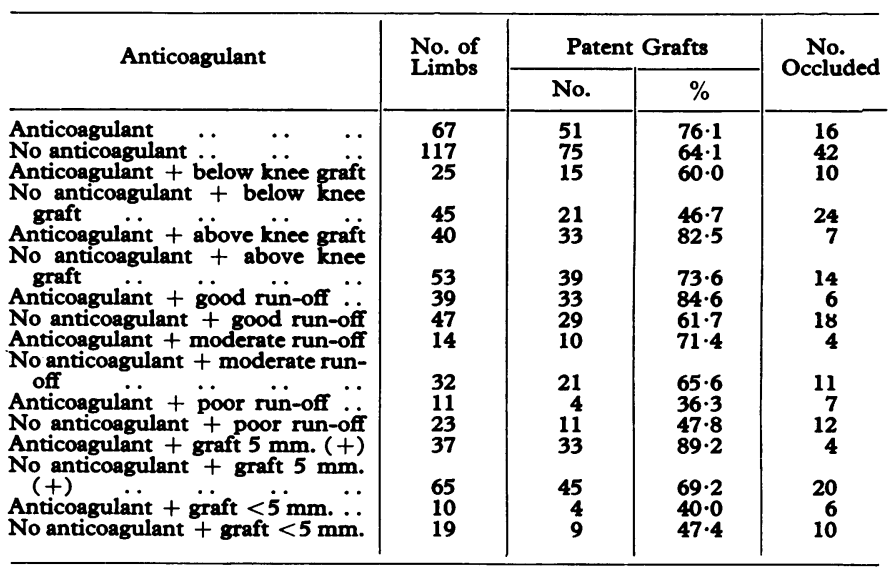

adjuncts to reconstructive vascular surgery. Overall they may confer a marginal benefit to graft patency, and this is seen with both above-knee and below-knee anastomoses. Good run-offs also appeared to benefit, but moderate and poor ones less so. The patency rate was greater when anticoagulants were used in grafts of $5 \mathrm{~mm}$. or more minimal diameter than when not, but with narrower veins there was no difference.

In our previous report we discussed a possible beneficial effect of anticoagulant therapy on the amputation rate in failed grafts. This impression is not sustained by our present figures. Of the 58 occluded grafts, 26 limbs required a major amputation, five of these patients having received anticoagulants. Regarding the remaining 32 unamputated limbs, only 11 of the patients had received this therapy; thus there is little difference between the two groups.

\section{Associated Disease}

Abnormalities of the electrocardiogram with or without a history of myocardial infarction were present in association with operations on 82 limbs. In these 54 grafts remain patent. Of the nine patients who died from myocardial infarction, eight had abnormal electrocardiograms before operation. Hypertension with a diastolic pressure of $95 \mathrm{~mm}$. Hg or greater was observed in 57 patients, and in $\mathbf{4 0}$ their grafts remain patent. Neither of these abnormalities appears to impair overall patency results and in view of the low operative mortality are not contraindications to surgery.

\section{Discussion}

The results of this survey are somewhat better than anticipated from our previous report and from those of MacGowan (1969) and Irvine and Williams (1969). We reaffirm that the autogenous vein bypass graft is the best available reconstructive procedure for femoro-popliteal occlusive disease. Our five-year patency rate of $61.5 \%$, however, is appreciably less than the $73 \%$ reported by Darling et al. (1967), but comparison with their results or those of others is impaired by differing case selection for reconstructive surgery. All our patients were severely incapacitated and bilateral femoro-popliteal grafts were performed in $11 \%$ of them. Reference to the published literature indicates that many American series contain a high proportion of patients whose sole complaint is that of claudication at distances in excess of 250 yards ( 230 metres) or so. Most British surgeons would not advocate reconstructive surgery in cases of this type since these have a relatively favourable outlook in terms of limb survival untreated. Our 
experience would certainly lead us to expect a late patency rate of $75 \%$ or so if we were to operate on appreciable numbers of such cases which we have not.

It is clear that siting of the distal anastomosis below knee joint level is a distinct disadvantage, regardless of whether the run-off vessels are good or poor and whether the graft is of adequate calibre. This may be related to kinking of the graft during flexion of the knee joint, and indeed several failures have been directly precipitated by long absorbing television programmes or protracted car journeys. Where possible we have preferred to site the anastomosis above knee-joint level as we felt that the disadvantage of kinking outweighs the risk of subsequent progression of atherosclerosis in the proximal popliteal artery, where its effects are more pronounced (Singer, 1963). Nevertheless, various authors (British Medical fournal, 1966; Sabga et al., 1968) have advocated the distal popliteal site of anastomosis as a routine; perhaps the best compromise is implantation of the graft at knee-joint level, though we do not have sufficient cases to assess this suggestion.

The minimal diameter of the autogenous vein graft should be $5 \mathrm{~mm}$., as we have noted that $45 \%$ of narrower grafts have occluded as compared with $23.5 \%$ of veins wider in diameter. Fortunately the long saphenous vein meets this requisite dimension in $75-80 \%$ of limbs. It is noteworthy that the combination of a narrow graft anastomosed distal to knee-joint level yields such a poor patency rate $(23 \%)$ that elective use of one of the newer prosthetic grafts (Ashton, 1968) may be justified.

The importance of a good run-off status has been clearly shown in this review and we are convinced that the extent of the disease has a most important bearing on late patency. Our results demonstrate that the four-year patency rate was $75 \%$ for patients with a good run-off as compared with $45 \%$ and $22 \%$ for patients with moderate and poor run-offs respectively. These findings again differ from those of Darling et al. (1967), and we therefore disagree with their suggestion that progressive distal atherosclerosis is not the basis of most graft failures. We have occasionally seen functioning vein grafts in limbs where advanced ischaemic rest pain and even gangrene necessitating amputation have gradually developed. Serial arteriography in such cases (Fig. 1) has shown progressive occlusion of the run-off arteries, and it is remarkable that some grafts are capable of function with such poor outflow.

It is gratifying to find maintenance of our limb salvage rate in patients at imminent risk of major amputation. The saving of three of every four seriously ischaemic limbs is in keeping with the findings of others and justifies full investigation and aggressive treatment of these patients.

The major problem in management of the femoro-popliteal problem now is the maintenance of patency in the functioning bypass vessel. If it is possible to minimize progression of distal atherosclerosis there seems to be little reason why these grafts should not remain patent indefinitely. To this' end complete

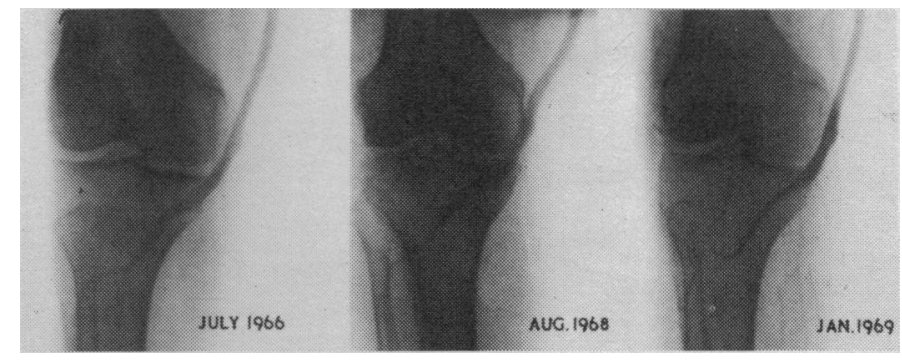

FIG. 1.-Progression of atherosclerosis in the distal popliteal and tibial arteries. The patient had a "good" run-off at the time of the initial graft procedure in 1963. In 1966, when the other leg was investigated, the posterior tibial artery had occluded. In 1968 she was suffering res pain and in January 1969 underwent amputation. At this stage the anterior tibial artery had occluded.

cessation of smoking is essential (Roth, 1951; Juergens et al., 1960) and lumbar sympathectomy as a routine in all cases may be worthwhile, not only for its immediate beneficial effect on the blood flow through the graft (Allan et al., 1968; Ghiringhelli and Demetz, 1968), but also to block the vasoconstrictor effect of nicotine which acts through the sympathetic nervous system. The case for long-term anticoagulant therapy remains to be proved, but the results may be marginally improved by these drugs.

It is a pleasure to acknowledge the help of our colleagues in the departments of anaesthetics, radiology, biochemistry, clinical, and pathology, as well as the Blood Transfusion Service. We are also grateful to the general practitioners who assisted in the follow-up of patients.

\section{REFERENCES}

Allan, J. S., Terry, H. J., and Taylor, G. W. (1968). Paper read at Surgical Research Society Meeting, Leeds, July 1968.

Ashton, F. (1968). British Fournal of Surgery, 54, 709.

Baddeley, R. M., Ashton, F., and Slaney, G. (1968). Surgery, Gynecology and Obstetrics, 127, 503.

Baddeley, R. M., Lawson, L. J., Ashton, F., and Slaney, G. (1967). British Medical fournal, 2,410

British Medical fournal, 1966, 1, 931.

Darling, R. C., Linton, R. R., and Razzuk, M. A. (1967). Surgery, 61,

DeWeese, J. A., Barner, M. B., Mahoney, E. B., and Rob, C. G. (1966). Annals of Surgery, 163, 205.

Ghiringhelli, C., and Demetz, A. (1968). Vascular Surgery, 2, 51

Gutelius, J. R., Kreindler, S., and Luke, J. C. (1965). Surgery, 57, 28.

Gutelius, J. R., Kreindler, S., and Luke, J. C. (1965). Surgery, 57, 28. Surgery, 10, 270.

Juergens, J. L., Barker, N. W., and Hines, E. A.; jun. (1960). Circulation, $21,188$.

Linton, R. R., and Darling, R. C. (1962). Surgery, 51, 62.

MacGowan, W. A. L. (1969). British fournal of Surgery, 56, 575. Roth, G. M. (1951). Tobacco and the Cardiovascular System. Thomas, Springfield, Illinois.

Sabga, G. A., Ferrato, P. J., and Young, W. V., jun. (1968). Vascular Surgery, 2, 135.

Singer, A. (1963). Archives of Surgery, 87, 384

Szilagyi, D. E., Smith, R. F., and Elliott, J. P. (1964). Archives of Sur-

Tillgren, C., Sténson, S., and Lund, F. (1963). Acta Radiologica Diagnosis, 1, 1161 . 